\title{
Erratum to: VEGF ligands and receptors: implications in neurodevelopment and neurodegeneration
}

Peter Carmeliet • Carmen Ruiz de Almodovar

Published online: 5 April 2013

(C) Springer Basel 2013

Erratum to: Cell. Mol. Life Sci.

DOI 10.1007/s00018-013-1283-7

The authors would like to publish this erratum to include Dr. Peter Carmeliet as the additional corresponding author of the article.

Unfortunately, the given name and family name of the corresponding author Dr. Carmen Ruiz de Almodovar were incorrectly published in the original publication. The correct given name and family name should read as 'Carmen' and 'Ruiz de Almodovar', respectively.

The online version of the original article can be found under doi:10.1007/s00018-013-1283-7.

P. Carmeliet $(\square)$

Laboratory of Angiogenesis and Neurovascular Link,

Vesalius Research Center, K.U.Leuven,

3000 Leuven, Belgium

e-mail: peter.carmeliet@ vib-kuleuven.be

P. Carmeliet

Laboratory of Angiogenesis and Neurovascular Link,

Vesalius Research Center, VIB, 3000 Leuven, Belgium

C. Ruiz de Almodovar $(\square)$

Biochemistry Center, Heidelberg University,

69120 Heidelberg, Germany

e-mail: carmen.ruizdealmodovar@bzh.uni-heidelberg.de 